Leigh Harrington*

\title{
"Helping you to pay us": Rapport management in debt collection call centre encounters
}

https://doi.org/10.1515/pr-2018-0013

\begin{abstract}
This paper investigates the rapport management (Spencer-Oatey 2005) that collections agents at a UK-based utilities company call centre are expected to perform during debt collection telephone interactions. It examines the rapport-relevant information communicated in the textual materials, including training manuals, through which a prescribed debt collection style is implemented. The analysis reveals that there are tensions in the rapport-concerns that collectors must attend to when using the style. Collectors are instructed to perform potentially face-threatening behaviours in order to collect debt, whilst simultaneously engaging in linguistic behaviour that may be interpreted as face-enhancing and which functions to develop rapport with the debtor. It is suggested that the local deployment of this contradictory "helping you to pay us" philosophy is problematic on multiple levels and may give rise to relational tensions between collectors and debtors who have conflicting expectations about rapport management entitlements. In turn, this may contribute to a culture of sanctioned face-attacks in call centres (Archer and Jagodziński 2015). Therefore, I suggest that call centres may need to loosen the synecdochical hold they have over their employees, thereby affording them the flexibility and volition to cope with the complex face demands, unpredictability and potential volatility of debt collection encounters.
\end{abstract}

Keywords: rapport management, face, call centres, debt collection, linguistic styling.

\section{Introduction}

As the prototypical example of a research site where the "language work" of employees constitutes the service work itself, it is unsurprising that the contemporary call centre (henceforth CC) has been a prolific subject of study for linguistic research (Cameron 2000a: 328). The sociolinguistics of globalization, for

*Corresponding author: Leigh Harrington, Faculty of Arts, Trent Building, University Park, University of Nottingham, United Kingdom, E-Mail: Leigh.Harrington@nottingham.ac.uk

Ә Open Access. (c) 2018 Leigh Harrington, published by De Gruyter. (c) BY This work is licensed under the Creative Commons Attribution 4.0 Public License. 
instance, has been attracted to the numerous practices CCs engage in to control the linguistic work of their employees (Hultgren 2011; Rahman 2009; Sonntag 2009). Existing (im)politeness research in CC contexts has focussed on challenges CC agents face when handling a customer's impolite behaviour (Jagodziński 2013; Orthaber and Márquez Reiter 2011). The complex power relations and face-considerations at play in CC interactions illustrate these challenges.

Whether "inbound" (caller initiated) or "outbound" (CC initiated), CC interactions take place between a CC agent (a public servant) and a customer (a private citizen) (Hood and Forey 2008: 400). Such extra-organizational contexts are characterized by an asymmetrical power dynamic between these interlocutors. Grandey et al. (2004: 399), for instance, observe that the popular mantra "the customer is always right" illustrates an agent's absolute "obligation to show deference to the customer" as a private citizen (Callahan 2006: 31). This power asymmetry goes some way to accounting for why the socio-discoursal role of a public servant can significantly limit the linguistic resources at their disposal. Culpeper et al. (2003), Bousfield (2007), Orthaber and Márquez Reiter (2011) and Jagodziński (2013), for example, have all empirically demonstrated how this limitation applies to managing a private citizen's impolite behaviour. The extent to which a public servant is formally "restricted by certain institutional codes of conduct" is heightened in CCs because of the lengths these organizations go to to control their agents' linguistic work, including scripting, styling and call-scoring assessments where quality analysts remotely listen to calls to evaluate an agent's performance (Limberg 2009: 1389).

Moreover, the "de-individuation" of agents as company representatives also "brings into play different aspects of face" in CC encounters (Archer and Jagodziński 2015: 55). As "intermediaries” between the organization and its customers, CC agents are engaged in a synecdochical relationship with the organization they represent, in which the agents act as the individual parts that outwardly represent the whole (the organization itself) to the customers (Grandey et al. 2004: 399). This relationship entails the management of personal face and professional face (Orthaber and Márquez Reiter 2011). Whereas personal face refers to the employees' individual faces, professional face represents "the professional persona" on loan to the agent, through which "the company presents itself to the public” (Orthaber and Márquez Reiter 2011: 3863). Agents must primarily protect their professional face as company representatives, whilst satisfactorily managing the customer's face (for the understanding of the customer's face in this study, see Section 4). Though personal face is usually a secondary concern in such a workplace context, it is inevitably entwined with professional face: consider how my experience of a customer criticizing the speed at which I calculated the term of a payment arrangement whilst working in a CC constituted both an 
attack on my professional competence and intellectual abilities (cf. Jagodziński [2013: 77-79] for an intercultural example of this). Verbal aggression directed at the agent from the customer is, therefore, not unusual; as "front-line" representatives, they often receive the brunt of customers' dissatisfaction (Grandey et al. 2004: 399). Customers may even use deliberately face-aggravating strategies to achieve extra-linguistic goals, such as to obtain compensation (cf. Bousfield [2010: 106] who argues that all impoliteness is instrumental, i.e., strategic to some degree). Whilst agent-directed aggression from the customer is common, it must be noted that evidence of the opposite, where agents have verbal outbursts which customers interpret as inappropriate and potentially impolite (Orthaber and Márquez Reiter 2016), and where agents react to impoliteness with impoliteness (Jagodziński 2013), has also been captured.

The pervasiveness of agent-directed face-attacks in CC encounters may suggest that these interactions are characterized by the "unidirectional" use of impoliteness, and the agents' powerlessness and subservience (Jagodziński 2013: 71-72). This is unsurprising given that conceptions of generic CC encounters are mainly predicated on the study of what is widely assumed to be the default CC activity: customer service, a definition of which is captured neatly by Merritt's (1976: 321) assertion that service encounters are "oriented to the satisfaction of the customer's presumed desire for some service and the server's obligation to provide that service". The prevalence of customer service encounters in CC scholarship is apparent to see. For instance, in a sociolinguistic investigation of globalization, Hultgren (2011: 38) identified features of linguistic styles prescribed for use in customer service interactions in six different languages, and termed this "a globally prescribed call centre style" in general (my italics). Whilst customer service is certainly an integral type of CC encounter, it is by no means every CC's raison d'être.

Warhurst and Nickson's (2007: 786) observation that to prevent academic accounts of service encounters becoming "myopic", researchers should be sensitive to the "increasing heterogeneity" of interactive service jobs also applies to linguistic research in call centres. (Im)politeness scholarship has already begun to reflect the diversity and potential complexity of call centre activity types beyond customer service alone. Jagodziński (2013: 51), for instance, has termed the airline call centre service encounters he examined a "superordinate category", which subsumes several sub-types of calls that have differing goals, such as sales calls and support calls, and acknowledges that a call may change sub-type mid-interaction. Likewise, Orthaber and Márquez Reiter (2011: 3860) have studied complaints calls to a Slovenian call centre, a different activity type in which the goals of the participants often explicitly "do not coincide with one another". This paper aims to further diversify the conception of CC encounters by exploring an as yet unexplored call centre activity type: debt collection. 


\section{Debt collection}

Debt collection (also referred to as credit control) is an activity type (Levinson 1992; Culpeper 2011; Culpeper et al. 2008) that is ripe for further diversifying the relatively homogeneous conception of CC encounters. Its distinctiveness stems from the fact that its primary communicative purpose (or macro speech act [Van Dijk 1977]) is to impose on individuals in order to recover money that they owe. It is fundamentally oppositional to the appeasement and "overwhelming emphasis on positive politeness" that is typically associated with customer service encounters (Hultgren 2011: 43), where positive politeness refers to the preserving of another's desire to be accepted, approved of and respected by others (Brown and Levinson 1987). Unlike most CC agents, collections agents do have the institutional power with which they can legitimately (at least attempt to) make a debtor abide by policies and regulations on behalf of their employers, which may include the threat of repercussion for non-compliance. Whereas complaints calls (Orthaber and Márquez Reiter 2011) often require agents to manage a customer's response to an initial (verbal or non-verbal) face-damaging phenomenon (cf. impoliteness “triggers" [Bousfield 2007: 2195]), in debt collection calls, collectors actually initiate the face-threat of requesting or demanding themselves. These potentially face-threatening speech acts (see Sections 5.0 and 5.1) are exacerbated in two ways in collection calls. Firstly, Márquez Reiter and Bou-Franch (2017: 664) consider how an unsolicited outbound call constitutes an intrusion on the customer's "private domain" per se. Secondly, our social attitudes towards money, at least in British culture, and the issues of emotion, power, risk and identity that it entails intensifies the imposition collectors make (Mooney and Sifaki 2017: 12). It is, therefore, unsurprising that Mooney and Sikafi (2017: 16) posit a characterization of debt collection communication as "phrased in official language, setting out obligations and conditions" to which debtors must adhere. Likewise, using interviews with over-indebted individuals to explore the behaviour of creditor avoidance, Custers (2017) found that debtors frequently had strong emotional reactions to their creditors' attempts to pressure them because they perceived them as unpleasant, threatening and even violent.

Debt collection is a call centre activity in which the potential bi-directionality of (im)politeness is bound up in a unique nexus of complex face-concerns and issues of power, legitimacy and obligation. Therefore, it is the aim of this paper to understand how debt collection agents are expected to negotiate the interpersonal dynamics of these encounters. For instance, are collectors explicitly instructed to be face-threatening and to use linguistic behaviour that may be perceived as unpleasant or threatening when dealing with customers in arrears? 
To address this research question, I will employ Spencer-Oatey's (2005) theory of rapport management, which is outlined below.

\section{Rapport management}

In her rapport management framework, Spencer-Oatey (2005: 96) positions the "management (or mismanagement) of relations between people" as an important motivation and macro-function of language use and outlines the factors that may influence people's dynamic perceptions of rapport - that is, the "relative harmony and smoothness of relations between people”. Recognizing what interactants may draw on in their evaluations of behaviour is essential if we are to understand how our judgements of, or orientations to, rapport may differ to one another, how they may change during an interaction and, ultimately, how social relations may be damaged, maintained and enhanced.

According to Spencer-Oatey (2005), there are three key components that we draw on when making rapport assessments: face sensitivities, interactional goals or wants, and behavioural expectations. This paper will focus on the latter. Behavioural expectations can derive from two interactional principles: the "equity principle” and the "association principle” (Spencer-Oatey 2005: 99). Referring to the fundamental belief that we are "entitled to personal consideration from others and to be treated fairly” (Spencer-Oatey 2005: 100), the equity principle captures an independent construal of self. This principle generates behavioural expectations about cost-benefit considerations, fairness and reciprocity, and that we should not be unduly imposed on or controlled by another interactant (autonomy-control). The association principle is an interdependent phenomenon, the "belief that people are entitled to an association with others that is in keeping with the type of relationship that they have with them" (Spencer-Oatey 2005: 100). It also has three components which refer to expectations about appropriate types of involvement we have with others, as well as the empathy and respect we perceive ourselves to be entitled to. Each of these expectations will vary according to the communicative activity at hand, as well as the specified roles of participants and the relationships between them.

Spencer-Oatey (2005: 97) asserts that behavioural expectations are also, in part, determined by communicative conventions, which may be formulaic in nature and, like the interactional principles, vary depending on the context of use. These communicative conventions may exist across five domains, through which rapport-relevant information is conveyed: the "illocutionary" domain refers to the performance of speech acts, the "discourse" domain includes the 
organization and management of an interaction, and the "participation" domain covers aspects such as turn-taking and verbal responses. Whilst the stylistic elements of an encounter are accounted for by the "stylistic" domain, the "non-verbal" domain pertains to proxemics and the use of gestures. Behavioural expectations are also informed by our beliefs about behaviours that are prescribed (socially obliged), permitted (allowed) and proscribed (forbidden). Moreover, Spencer-Oatey (2002: 542) observes how "relational tensions" can occur when participants in an interaction have different motivations, or focus on or have differing expectations about appropriate rapport management concerns. To understand how collections agents are expected to negotiate the interpersonal dynamics of collections encounters, I will also draw on rapport management's notion of identity face. Unlike respectability face, which Spencer-Oatey (2005: 103) asserts is pan-situational, identity face captures face that is "threatened or enhanced in specific interactional encounters", such as collections calls. I would like to propose that rapport management is a suitable framework for pragmatic investigations of prescriptive linguistic styling in CCs in two ways, outlined below.

\subsection{Rapport management, corporate linguistic styling and linguistic idealization}

Rapport management's notions of prescription, proscription, behavioural expectations and communicative conventions have particular salience for CC interactions; CCs engage in explicit codification practices that aim to ensure the linguistic routinization and uniformity of their staff, and in doing so may repress linguistic diversity (Leidner 1993; Cameron 2008; Rahman 2009; Sonntag 2009; Hultgren and Cameron 2010). In other words, in a top-down fashion they prescribe and proscribe different aspects of language use that cover each of Spencer-Oatey's domains, from specific lexical choices to tone of voice, such as to create communicative conventions for performing different CC tasks (cf. prescriptive rules as a type of metapragmatic comment [Culpeper 2011: 74]). Rapport management's five domains, especially the stylistic one, are relevant here given that one of the most central and explicit of CCs' regulatory activities is the process of corporate linguistic styling, the "object/product" of which is the style that is prescribed to customer-facing employees (Cameron 2000a: 324).

CC scholarships' conception of style both shares similarities with and differs from more typical sociolinguistic definitions. CC conceptions map onto Moore and Podesva's (2009: 448) notion of styles as "clusters of features" which pertain to all levels of language, from "individual sociolinguistic variables", to "personal pronouns" and "politeness strategies" (Bell 2009: 270-271). However, the two 
diverge when it comes to individual volition. In sociolinguistic conceptions, style usually inherently carries "that speakers have alternatives or choices - a 'that way' which could have been chosen instead of 'this way”' (Bell 2009: 265). In the CC context, however, agents' individual choice is subjugated to a corporate norm. They are largely (though not necessarily completely) relieved of the responsibility of making spontaneous stylistic judgements and adjustments; they are not their own "stylistic agent" (Eckert 1996: 4) who carries out their own "self-styling" autonomously (Cameron 2000a: 326).

That the shaping of the CC agents' linguistic resources takes place beyond their influence is comparable to Bell's (2009) findings on the styling of New Zealand radio presenters. He identified that broadcasters' individual styles are "routinely subordinated to a shared station" style whose character can only "be explained in terms of its target audience" (Bell 2009: 268). This finding focalizes another defining characteristic of styling which also applies to CCs: it is oriented to people and, hence, can be strategic. Styling can be designed with a specific audience in mind and with the intent of provoking a (favourable) response from or having a (desirable) effect on that audience according to a particular communicative goal, e.g., to appease or to persuade. The strategic nature of styling is reflected in rapport management theory's tenet that a key motivation of language use is the effective management of relations between people. As Spencer-Oatey (2005: 107) avers, when people have specific interactional goals or wants, especially transactional ones that require relational work, we may consciously manage interactions in a way that enhances, maintains or even damages rapport.

Synthesizing a framework that accounts for motivated language use with the strategic design of corporate linguistic styling promises to be an effective means of exploring what rapport management collections agents are expected to perform in debt collection interactions. This synthesis also represents a timely endeavour for pragmatics research in CCs. The presence of prescriptive linguistic practices is indicative of a widespread culture of linguistic idealization. Jagodziński (2013: 45), for instance, draws parallels between Brown and Levinson's (1987) Model Person and the creators of CC training manuals constructing an "ideal agent" who always successfully deals with a customer in the maximally appropriate way. Yet, linguistic idealization through styling has primarily been a sociolinguistic topic, not a pragmatic one (Cameron 2000a; Rahman 2009; Sonntag 2009; Hultgren 2011).

Existing research has considered the macro-implications of consciously appropriating linguistic features to design a prescribed style, such as how indexing social groups or categories can be problematic. For instance, Cameron (2000a) draws parallels between prescribed customer service styles in CCs and 
stereotypical conceptions of feminine interactional styles. Identifying the desirable symbolic qualities workers index through customer service styles, such as appeasement and subservience, she concludes that a conventionalized correlation between feminine language and good customer service is desirable and, hence, perpetuated. Likewise, Rahman (2009) found that prescriptive linguistic practices and policies in outsourced CCs in Pakistan, especially the neutralization of accents to resemble that of British and American customers, positions workers in states of conflict regarding regional and cultural authenticity. This, in turn, contributes to the ideologically constructed hierarchical order of both accents and languages in Pakistan. Using rapport management theory to analyze the interpersonal work a prescribed style is expected to perform in practice offers (im)politeness research a way of tapping into the more local interactional implications and potential complications of linguistic idealization in CC contexts.

\section{Methodology}

To determine what rapport management work CC agents are expected to perform in debt collection encounters, it is necessary to understand how these agents are trained and instructed to conduct themselves. Prescriptive textual materials, which Heller (2003: 481) glosses as a collation of "in-house call centre documents and instruction manuals", have been successfully employed for these purposes; Cameron (2000a: 328) asserts that they provided her with the "clearest and most detailed picture of what linguistic ideal a call centre 'officially' wants its operators to aim for, what it prescribes and proscribes". Therefore, this study's primary data type are the same in-house materials that a large utilities company based in the UK used to disseminate its prescribed debt collection style to its employees. Since the company in question has asked to remain anonymous, it will be referred to by the pseudonym Electrik throughout this paper.

Access to in-house materials was possible as a consequence of the trustworthy relationship I had developed with Electrik by working as a debt collector during spells across a three-year period between 2010 and 2013. Re-contacting Electrik and explaining my interest in researching how debt collectors speak to customers, I was permitted to return to the site as a researcher to conduct an observation day during which I listened to calls, conducted semi-structured interviews with collectors (see below), and acquired copies of the three main tools through which corporate linguistic styling was exercised: a training manual called "How to collect debt” (HTCD, 31 pages), a call quality guide (CQG, 4 pages), and a set of call-scoring criteria for collections calls (CSC, 4 pages). Whilst HTCD and CQG 
exemplified the "skills, knowledge and behaviours a successful debt collector should have”, the CSC contains up to 37 components against which agents' performances of outbound calls were evaluated in different phases of the encounter. Example 1 below, for instance, is taken from the "Payment Request" phase:

\section{Example 1. (CSC)}

Stated full outstanding balance and payment due date or period debt relates to and asked for payment in full by db/cr card today

In delineating not only what the collectors must say and how they must say it (prescriptive behaviours) but also that which they must avoid (proscriptive behaviours), call-scoring criteria embody "probably the most important instruments of styling” (Cameron 2000a: 332). Collectors usually had 5-10 calls scored per month at random and could earn minor financial bonuses from consistently high call-scoring marks. Unlike many corporate sales environments, they did not receive commission for debt collected. Consistently low scores were a cause of concern for the employer, and extreme cases of unimproved performance could result in dismissal.

The eight interviews I conducted with collectors took place either on site during the observation day or at a neutral venue, and lasted around 30 minutes each. Semi-structured in design, they were intended to "elicit insiders' perceptions of call centre work" broadly and the collectors' experiences of the linguistic expectations and monitoring they were subject to through styling (Cameron 2000a: 329). As there is not space to analyze them in full here, the interviews will be drawn upon as an additional evidence base in the Discussion (Section 6).

Debt collection fell within the remit of Electrik's Risk and Debt Management department, which contained a dedicated collections CC that specifically dealt with SMEs (small and medium enterprises). Collections is particularly important in the utilities industry because of the custom to pay for consumption retrospectively. It was mentioned in Section 1 that agents must primarily protect their professional face as company representatives, whilst satisfactorily managing the customer's face. A more detailed examination of the relationships between Electrik collectors and their SME customers, and the type of face at stake in these encounters is necessary. Given that SMEs are businesses, it would seem, therefore, that the collections encounters examined here usually take place between Electrik representatives (agents) and representatives of the organizations in arrears (customers). By extension, it would seem reasonable to assume that in such business-to-business interactions, the customer's face that a collections agent is required to manage is of a similar make-up to their own, in that the projection and protection of professional face is prioritized over that of personal face. 
However, the potentially diverse nature of SMEs means that this is not always necessarily the case. The composition of professional and personal face at stake for the customer in collections encounters may vary significantly according to the size of the enterprise and the level of personal investment the customer has in it. Whilst many SMEs do, like larger organizations, have employees that represent the enterprise as a whole, in my experience of working in this context, there are also many micro-enterprises (that employ fewer than 10 people) where the employees are not engaged in the same synecdochical relationship with the enterprise at hand. Consider how a takeaway owner who lives above the business with their family, or the widow of a lone farmer who has been left to manage their spouse's accounts may more closely resemble a domestic account than a commercial one (both are situations I came across whilst working for Electrik). The amount of the customer's personal face at stake in such collections encounters tended to equal or surpass that of their professional face. Therefore, it must be acknowledged that as customers SMEs are a heterogeneous group, meaning that the types and amount of face that collections agents may have had to manage varied. Yet it is still worth reiterating that the relationship between the participants in these encounters is still essentially that of an agent and a customer, regardless of the nature of the SME.

Although my established relationship with Electrik, as well as clearly communicating the aims of the research, was conducive for collecting textual data, I was unable to access the recordings of authentic collections calls which I had initially requested. Unfortunately, Electrik stated that all data relating to customers can only be used for the purposes which are known to them at the point at which they register with Electrik. For instance, this includes calls being recorded for monitoring and training purposes, but not for research. This is indicative of the challenges facing researchers in many service industries, not only call centres. As Hood and Forey (2008: 390) assert, the numerous complications regarding confidentiality and data protection compliance that surround accessing interactive data represents a "significant methodological hurdle" of this research site. However, a limited number of recent studies have demonstrated that this hurdle is not always insurmountable (Jagodziński [2013], Orthaber and Márquez Reiter [2011] and Harrington [forthcoming], amongst others).

\subsection{Debt collection tasks}

At the time of data collection, once a customer was billed, they had two weeks to clear the given balance. If payment was not received promptly, the account was then passed down the "collections path" which consisted of four stages 
and included the two dominant modes of contact in the UK collections industry, letters and phone calls (Deville 2015):

Stage 1: reminder letters

Stage 2: $\quad$ statutory notice

Stage 3: $\quad$ outbound telephone contact

Stage 4: the account is passed to an external debt collection agency

The analysis that follows refers to the prescriptive style that was employed in stage 3, outbound telephone contact. It will primarily employ the five domains through which rapport-relevant information can be conveyed, as well as the interactional principles of equity and association and the notion of identity face (see Section 3). As previously noted, as well as employing these tools from rapport management, I also draw on my own experience as a member of this particular debt collection call centre Community of Practice (Wenger 1998; Eckert and McConnell-Ginet 1999; Mills 2003) in order to make first-order evaluations and interpretations of which linguistic behaviours are intended to threaten face and to enhance face.

This paper uses a data type that primarily accounts for the expectations of rapport-relevant information conveyed by a prescribed linguistic style. Although prescribed styles are predetermined, the interactions in which they are designed to be used are, of course, spontaneous and dynamic, and meaning is co-constructed between the participants. After all, the customers' responses to prescribed behaviour cannot necessarily be anticipated. Nonetheless, the analysis of prescriptive textual materials in this way offers a refreshing insight into the interpersonal work a CC agent is intended to perform, as well as the potential consequences of such linguistic codification practices in service industry contexts.

\section{Analysis}

This analysis examines the rapport-relevant information that Electrik's prescribed debt collection style is intended to convey when used in collections encounters. It reveals that the prescriptive textual materials contained two sets of linguistic features that adopt very different orientations to managing rapport. As will be shown, whilst one set intuitively performs the imposition of collecting unpaid money and aligns with conceptions of debt collection communication as face-threatening, interestingly, the other set does not. 


\subsection{Face-threatening features}

The distinction between the transactional and relational functions of language is well established in sociolinguistic literature. Transactional talk typically "describes activities that primarily aim to get things done, solve problems and achieve set goals" (Schnurr 2009: 3) and relational talk guides "the way in which people relate to and present themselves to one another" (Koester 2006: 26). Whilst the two are indivisible, Koester (2006: 53) asserts it is possible to identify whether talk shows "a stronger orientation towards either transactional or relational goals". The first set of features examined here conveys that it is desirable for collectors to adopt a more transactional approach to collections interactions rather than a relational one. Therefore, the maintenance or enhancement of rapport between the collector and customer is not prioritized. The communicative conventions that are set up exist across each of Spencer-Oatey's (2005) domains, other than the non-verbal.

Firstly, let us consider the discourse domain - that is, the ways in which collectors are instructed to manage the unfolding discourse. As Example 2 illustrates, Electrik's call-scoring criteria stipulates that the collector should be "in control" of collections interactions at all times:

Example 2. (CSC)

In control

Autonomy-control is a component of the equity principle, the right to not be unduly controlled or imposed on. Numerous linguistic devices through which this control might be achieved are prescribed. Firstly, small talk is strongly discouraged. That this is proscribed may be a reflex of what Hultgren (2011: 49) identifies as the "constant tension" between efficiency in terms of time and outcomes in CCs, in that small talk may reduce worker productivity by extending call times. However, given that in a variety of other contexts, a function of small talk is to attend to positive face wants and to "establish, maintain or renew social relationships", its overt omission from this style may also suggest that linguistic behaviour which sustains or enhances rapport is considered superfluous to collecting debt (Holmes 2000: 49; Mullany 2006).

Closed questions and using the superior factual information at the collector's disposal are positioned as important techniques in the collector's "arsenal" for controlling the call. To elicit "specific information and confirmation" from the customer, targeted questions should be utilized. To address, neutralize or combat any objections, the collector should "demonstrate knowledge of debtor's account history" by using key facts, as in Example 3: 


\section{Example 3. (CSC)}

Stated the facts to demonstrate knowledge of debtor's account history (Score 1-5)

The style's transactional orientation to rapport is pervasive, not only in the way that it attempts to regulate the worker, but also in the way that it instructs the collector to influence the customer's approach to their encounter. The training manual in particular creates a dichotomous relationship between an undesirable "emotional" approach and a desirable "logical" approach to money; as Mooney and Sifaki (2017: 12) posit, whilst in the abstract, money may appear to be "rational, impersonal and logical", in the particular it is "always bound up in questions of identity, obligation, risk, power and emotion”. As Example 4 below shows, avoiding small talk, using facts and closed questions equips the collector to get the customer to get "into a logical way of thinking":

Example 4. (HTCD)

\section{Why is this important to a collection call?}

Be logical - breakdown facts.

Disconnect with customers emotional side (their reaction - the way it makes them feel) to get them into a logical way of thinking.

Similar rapport-relevant information is perceptible in the style's participatory domain, two features of which represent infringements to the debtor's equity rights. Like the proscription of small talk, the prescription to interrupt customers prevents them from speaking tangentially and prolonging call times. However, interruption is also positioned as a device for the collector effectively "controlling" or regaining "control of the conversation”. Deliberately preventing a debtor from completing their conversational turn not only reduces their entitlement to autonomy but, under the association principle, it also damages their rights to respect and their due involvement in the interaction.

In most service encounters, an agent traditionally uses the "hold" telephone function for the customer's benefit, such as to give themselves space to investigate a query that has been raised. However, in this data, hold is positioned as one of the most powerful weapons through which a collector can control a call, especially during a negotiation. Example 5 demonstrates this: 
Example 5. (CSC)

Use hold to your advantage, especially in negotiation. You must return to the customer within 3 minutes.

Use hold (remember to return within 3 mins - use time to write note) to add pressure to the debtor

Bought time after asking for increase in first offer (Put on hold)

For instance, when a customer has made an initial payment offer which is then refused, collectors are instructed to use hold to their "advantage" to buy time and "put pressure on [the] debtor" to increase their offer. This imposed silence is prescribed as a restrictive measure and pressurizing tactic (cf. Jaworski 1993; Kurzon 2007; Jagodziński and Archer 2017). Depriving a debtor of constant engagement and physically dictating their opportunity to speak is a significant imposition to both their equity and association rights. Again, as a method of managing the unfolding discourse, collectors are asserting their power over the debtor in the encounter by communicating little concern for the debtor's identity face and for maintaining or enhancing the rapport between them.

The instruction to be controlling is reinforced by the rapport-relevant information that the stylistic aspects of the prescribed style convey. The inclusion of the widely misquoted Mehrabian (1968) myth regarding the role of tone of voice in message comprehension in HTCD illustrates the importance placed on the collectors' effective use of suprasegmental phenomena:

\section{Example 6. (HTCD)}

\section{The Importance of Tone of Voice}

It's not what you say, but how you say it

Ever heard that expression?

Tone of voice can account for up to $38 \%$ of how a spoken message is comprehended over the telephone.

Collectors are expected to appear authoritative and "assertive at all times" and so are instructed to employ assertive (yet not aggressive) tones of voice (see Example 19, however). As Example 7 shows, they must also avoid hesitation, hedging, or any other "expressions that reduce the force of an utterance" or convey lack of certainty or commitment (Cameron 2000b: 131). 
Example 7. (CSC)

Assertive, not aggressive. Avoid using terms such as 'Erm', 'Eh'

Assertive at all times

That the "strength" of the tone used during the payment request will be "picked up" on in the collectors' call-scoring is indicative of the emphasis placed on the collector appearing "confident” during the crucial part of the call:

Example 8. (CQG)

Provided account Advisor requested payment mentioning account number number, outstan- and the outstanding balance and confidently requests ding balance and payment: requested full "I'm calling with regards to account number $<>$, there is an payment outstanding balance of <> and I'm calling today to collect the full balance over the phone by debit or credit card"

${ }^{\star}$ Note $^{\star}$ - asking for payment scores as a pass. Strength and tone of request would be picked up in feedback.

Interestingly, the rapport-relevant information conveyed by the stylistic features of this style are geared towards the collector's correct presentation of self to the debtor, presumably with the expectation that this will contribute to the successful collection of debt.

The tone through which the payment request should be made leads me onto the communicative convention created in the illocutionary domain, namely the request for payment itself. The importance of this speech act in collections encounters is epitomized by the fact that Electrik provide collectors with a word-by-word script for executing it (Austin 1962; Searle 1976). According to the call-scoring criteria, deviation from the script which is given below results in an automatic fail:

Example 9. (CQG)

I'm calling with regards to account number $<>$, there is an outstanding balance of <> and I'm calling today to collect the full balance over the phone by debit or credit card

This third clause is not a maximally direct demand, such as an imperative "pay us now". Likewise, it does not offer the same level of mitigation and optionality implicit in an interrogative, such as "are you able to make a payment today?". 
In fact, framed as the declarative "I'm calling today to collect the full balance over the phone", this payment request does not strictly request syntactically at all. However, this declarative is likely to be perceived as face-threatening because it employs confirmation-seeking components that are "presumptively designed" and highly entitled by immediately announcing the collector's interactional wants and expectations (Speer and Stokoe 2014: 61). This fait accompli grammatical construction makes the debtor's refusal dispreferred at best. Eradicating choice is a significant threat to the debtor's identity face and imposes on their rights to act unimpeded. Performing this speech act in a manner that asserts absolute obligation again epitomizes the style's priority to obtain payment.

Since debtors often cannot make a full payment, collectors must negotiate with them to take a part-payment or arrange a payment plan. Throughout the calls, but in this negotiation phase in particular, collectors are instructed to be direct and logical, and to continually assert their authority and power by:

(1), displaying "tenacity" to challenge and question what the debtor says, especially if it is inconsistent with the facts that the collector can see on the computer systems:

Example 10. (CSC)

Demonstrated tenacity to get past gatekeeper (if applicable)

Ask questions to establish if debtor is a “can’t pay” or a “won’t pay” e. g. "why do you always pay outside the terms and conditions of your supply", "why have you not called us", "why have you not provided a COR”. You should challenge/ question what the debtor says, especially if it contradicts the information on the account

(2), challenging any excuses or any attempts to deceive:

Example 11. (CSC)

Challenged fob-off e.g. "I’ve sent a cheque", "I'll call tomorrow" etc.

and, (3), declining the customer's first offer if it is not the full balance. Additionally, the data states that any agreements that are arrived at must be obtained on the "collector's terms" which appears to disregard the fairness and reciprocity component of the equity principle: 
Example 12. (CSC)

Always refuse the first offer (unless full balance offered)

Obtained agreement on Collector's terms

From this first set of communicative conventions for collecting debt, we can make an initial assessment of the rapport management work that the collectors perform when using this prescribed style. It may be a stretch to say that the evidence so far aligns with Custers' (2017) assertion that debt collection communication can be unpleasant, threatening and violent; the features are not explicitly prescribed with the intent to damage rapport between the interlocutors or to damage the customer's face. However, the rapport-relevant information conveyed so far does demonstrate that the maintenance or enhancement of relations between the two interlocutors is not prioritized; impinging on the debtor's right to autonomy and self-directed control in particular, and not attending to the interactional principles of equity and association more broadly, may well be interpreted by the customer as face-threatening behaviour. The analysis also revealed a second set of linguistic features which adopt a very different orientation to managing rapport than that outlined in the first half of this analysis. As will be shown, this set closely aligns with the relational work that CC scholarship identifies as typical of customer service interactions - that is, these aspects of the style are face-enhancing and do convey a concern for building or maintaining rapport between the collector and customer. This set of communicative conventions for collecting debt also exist across each of Spencer-Oatey's (2005) domains, including the non-verbal.

\subsection{Face-enhancing features}

In contrast to the transactional orientation outlined above, the style also explicitly instructs collectors to "create rapport” with Electrik's customers. This signals that collectors are also expected to perform relational work that aims to enhance rapport, whilst obtaining payment. The style prescribes several linguistic devices through which collectors should build rapport. As Example 13 illustrates, in terms of the discourse domain, there is the general prescription that, during collections interactions, the collector is:

Example 13. (CSC)

Polite and courteous at all times 
"Polite" and "courteous" are first-order terms which recognize how Electrik themselves orient to and understand notions of politeness in social behaviour (Locher and Watts 2005: 15). In my experience of this context, the explicit use of "polite" and "courteous" broadly means to show respect and consideration for others. These instructions seem antagonistic to the rapport-relevant information that communicated the need to exercise imposition and control. Whilst it is possible to be both assertive and polite, this is a delicate balance. For instance, although they are prescribed for controlling the call, the data warns that excessive or exclusive use of closed questions has the undesirable effect of "stunting rapport" with the customer. Hence the use of open (WH-syntax) questions is also prescribed. Open questions that promote extended talk are encouraged, yet there is no place for small talk in this style. Questions that give customers the space to talk at length have the opposite effect of participatory features like interruption and imposed silence (hold) which infringe on the customer's rights to autonomy, respect and due involvement. That building rapport is a stated "benefit" of open questioning techniques in Example 14, signals that there is some positive relational work required in collection tasks:

Example 14. (HTCD)

Benefits of this style

[open questioning]
Gain more information

Build rapport

Hence collectors should "use open and closed questions at the correct time" to manage the encounter (HTCD). This is a very rare, if not the only, example in the data where a collector is granted some degree of stylistic license. However, the reference to the "correct time" above and "effective questions" below rather undercuts this sense of autonomy, suggesting that the collectors may indeed make choices, as long as they understand those choices will be subject to evaluation:

Example 15. (HTCD)

'Effective questions open the door to knowledge and understanding'

Another aspect of the set of features that orients towards developing rapport between interactants is the recurring expectation that collectors empathize with the customer: 
Example 16. (CSC)

Empathised where appropriate

Empathy not necessarily sympathy. Show debtor that you understand and have listened to what they have said

Although the exact difference between empathy and sympathy is not substantiated in the data, in my experience as a collector, empathy points to the collector's ability to show a debtor that they do "understand and have listened to what they have said". Sympathy, however, refers to the development of a personal involvement or investment in the debtor's circumstance that may detract from the job at hand. Whilst displays of empathy maintain greater social distance between collector and debtor than sympathy, they do nonetheless contribute to positive, interdependent construals of self; in being empathetic, the collector demonstrates respect and shares concerns with the debtor that are appropriate to the context. Demonstrating empathy can be especially important during collections calls, as debtors can find themselves in difficult personal circumstances that create or contribute to financial hardship (see the discussion of face and different SME types in Section 4). Custers (2017: 181) has pointed out that it can be counterproductive to the whole collections procedure when creditors disregard the struggles occasioned by debt. She observes that "when the emotional reality of an indebted life is met with empathy, both the emotional and financial outcomes are very different compared to when it is met with threats and mercilessness" (Custers 2017: 181).

The most interesting aspect of this dataset entails a Janus-faced orientation to the face concerns of the debtor (cf. Jagodziński 2013: 81). When handling angry, volatile or even abusive customers, collectors are instructed to facilitate the customer's extended talk by withholding their own contributions. The collector should appear supportive, engaged and attentive by observing the debtor's rights to speak freely, have appropriate involvement in the interaction, and respect. However, the use of silence in this way is positioned as a technique through which the collector can exercise more subtle control over the debtors than the overt imposition created by interruption or imposed silence (hold). HTCD suggests that once a debtor has been allowed to "speak and vent their frustrations freely", a collector will be better placed to regain the conversational floor or "control of the conversation" in a way that benefits the successful recovery of debt. Therefore, I am categorizing the prescribed use of silence in this way as a falsely facilitative rapport-building device; whilst it appears to be face-maintaining and fosters debtor autonomy and positive rapport, in fact it is another instrument for the collector to control the unfolding discourse. For that reason, this aspect of the style might be classed as a variant of Culpeper et al.'s (2003: 1566) 
“insincere agreement” strategy. Insincere agreement seeks to manage an impolite act defensively, by allowing a speaker of the act to "let off steam" or by expressing surface agreement with the initial attack.

Perhaps the most striking contradiction in the data occurs in the rapport-relevant information communicated by the participatory domain. On the one hand, certain linguistic techniques, namely interruption and imposed silence, are used to restrict the debtor's involvement and freedom. On the other, collectors are prescribed to use devices which position them as engaged with, interested in and attentive to the debtor, as per the association principle. In HTCD, for instance, a section is dedicated to "How to show that you are listening?" [sic].

Firstly, to demonstrate they are listening to "what the customer is saying”, the collector should perform active listening by using supportive minimal responses, or "verbal nods", such as "okay" and "I see", alongside open questioning. The style's verbal nods closely resemble the "key phrases" that Hultgren (2011: 44) observed are prescribed to customer service agents. Given that collectors are instructed to interrupt the debtor, the style's prescription to also "avoid talking over" them seems fundamentally antagonistic:

Example 17. (CSC)

Actively listened and responded accordingly

Listen to what the customer is saying, avoid talking over them

Secondly, the use of "positive response phrases" listed in Example 18 below are explicitly positioned as functioning to help the collector create rapport with the debtor, especially if faced with dissatisfaction or objection:

Example 18. (CQG)

$\begin{array}{ll}\text { Provided positive } & \text { Advisor creates rapport and understanding of the custo- } \\ \text { response } & \text { mers objection by using a positive response phrase: } \\ \text { to objection } & \text { "I'm sorry to hear that" } \\ & \text { "Thank-you for letting me know" } \\ & \text { "Thanks for that information" }\end{array}$

In terms of the stylistic domain, it has been shown that strong, confident and assertive tones of voice are obligatory (Examples 7, 8). However, Example 19 also states that these assertive tones must not sound aggressive, rude or patronizing: 
Example 19. (CQG)

Prevents escalation of conflict by avoiding aggressive, rude or patronising tones, language or behaviour

Like displays of empathy and sympathy, the threshold between assertive tones and aggressive ones is not clearly delineated. Yet the fact that the proscription of these tones prevents conflict from escalating illustrates that potential damage to the rapport between collector and debtor should be avoided. Complementary to this is the fact that collectors must also "insert inflections" into their speech and "use variance" in their tone:

Example 20. (HTCD)

\section{- Maintain good posture}

Project voice, sound interested etc.

- Insert inflections into your speech

Use variance \& interest

Interestingly this excerpt contains an attempt to style an aspect of the collectors' non-verbal behaviour, their posture, which is relatively unusual in telephone communication. The prescription that collectors "sound interested and enthusiastic" and "make customers feel like they can approach us [Electrik]" mirrors Cameron's (2000a: 334) findings that customer service workers traditionally appear appeasing by avoiding "intonation which will be heard as monotonous or uninvolved" and attend to customers' positive face wants (Brown and Levinson 1987). The styling of voice in this way appears to position collectors as obligated to closely attend to the customer's identity face sensitivities.

Finally, an element of the call-scoring criteria referred to the collectors' lexis. The specification that they must "avoid [industry-specific] jargon" during collections tasks is consistent with Hultgren's (2011: 46) observation of the same practice in prescribed customer service styles:

Example 21. (CSC)

Avoided jargon

Remember, most of our abbreviations are internal abbreviations which the customer will not know. Avoid at all times

Instead of imposing Electrik's own vocabulary on the debtor, collectors are instructed to make stylistic shifts to mirror the customer's own terminology. This sort of conscious linguistic convergence aligns with Archer and Jagodziński's 
(2015: 52) notion of the "customer service ideology", which assumes that the use of jargon "unduly emphasises the call centre's expert power". In avoiding specialist jargon, therefore, Electrik might be said to be instructing the collector to forge a balanced and reciprocal relationship with the debtor in which their "social and communicative differences" are diminished (Giles 2009: 278). This contrasts markedly with the image of a collector who is challenging (Examples 10,11) and controlling (Example 2).

Sections 5.1 and 5.2 above generated an overall characterization of the prescribed debt collection style and the rapport management work that collectors are instructed to perform in collections encounters. Both are summarized in Table 1 below. Whilst that given on the left is what we might intuitively associate with the prototypically face-threatening nature of debt collection, that given on the right is traditionally established with the face-enhancement, appeasement and subservience of customer service styles.

Table 1. Analysis Summary

\begin{tabular}{|c|c|}
\hline Debt Collection Tasks/Styles & Customer Service Tasks/Styles \\
\hline \multicolumn{2}{|l|}{ Rapport-relevant information conveyed } \\
\hline \multicolumn{2}{|c|}{ Primary Interactional Goal (Macro Speech Act) } \\
\hline Take immediate payment (imposition) & Retain future custom (appeasement) \\
\hline \multicolumn{2}{|l|}{ Call Orientation: } \\
\hline Primarily transactional & Primarily relational \\
\hline Disregard rapport, face-threatening & Create rapport, face-enhancing \\
\hline \multicolumn{2}{|l|}{ Equity Principle: } \\
\hline Control interlocutor & Promote interlocutor's autonomy \\
\hline Impose on interlocutor & Listen to interlocutor \\
\hline
\end{tabular}

\section{Association Principle:}

Dictate interlocutor's involvement

Encourage interlocutor's involvement

Share appropriate concerns

Show respect

Role Specifications:

Collector: Empowered, entitled Debtor: Disempowered, indebted
Collector: Disempowered, indebted

Customer: Empowered, entitled 


\begin{tabular}{ll}
\hline Prescribed Linguistic Features \\
\hline Illocutionary Domain: & N/A \\
\hline Fait accompli scripted declarative & \\
\hline Discourse Domain: & Open questions \\
\hline Avoid small talk & Demonstrate empathy \\
\hline Closed questions & \\
\hline Use facts & \\
\hline Silence (insincere agreement) & Active listening \\
\hline Participatory Domain: & Positive response phrases \\
\hline Interruptions & \\
\hline Imposed silence (hold) & $\begin{array}{l}\text { Emotionally expressive intonation, avoid rude } \\
\text { or patronizing tones } \\
\text { Stylistic Domain: }\end{array}$ \\
\hline Strong/confident/assertive tones & Avoid jargon (mirror lexis) \\
\hline
\end{tabular}

\section{Discussion}

The amount of information captured by Table 1 alone demonstrates that the prescribed debt collection style demands a lot of its users. This discussion will firstly consider why the contradictions in the style's approach to rapport are discernible. It will then address how these contradictions may be problematic to both the style's users and its intended recipients, before considering some possible solutions.

\subsection{Accounting for contradictions}

Why has it been possible, then, to identify linguistic features that are associated with being face-enhancing in a style that is designed to perform an activity that is prototypically face-threatening? Further examination of the data revealed that some of the in-house materials were disseminating inconsistent intracultural premises. For instance, the data's own definition of debt collection tasks revealed a potential duality in the style's intended purpose. A section in HTCD 
which described each department's responsibilities positioned debt collection as a "function of" customer service rather than independent from it:

Example 22. (HTCD)

\section{What do the teams do?}

\section{Risk and Debt Management}

Responsible for delivering cash collection targets and minimising bad debt to the business. R\&DM provide a vital customer service function and aim to resolve any difficulty in payment our customers may experience by providing a range of options and budget plans. We also deal with de-energisation of supplies for nonpayment, protecting the business from bad debt.

This definition suggests that the prescribed debt collection style was not designed solely for collecting debt; collectors were being expected to execute debt collection and customer service tasks in the same call and, hence, with the same linguistic style. At the outset of this paper, I asserted that debt collection is fundamentally oppositional to customer service in terms of communicative purpose (or macro speech acts). In unifying the communicative goals of customer service and debt collection, the collector is expected to simultaneously perform relational work that sustains or promotes positive relationships in the future, whilst also successfully executing a transaction that necessitates a high degree of assertion and imposition. In view of this, it is unsurprising that what I have termed falsely facilitative rapport-building devices are prescribed, such as the collector using silence to appear face-maintaining whilst indirectly controlling the unfolding discourse. It is worth reiterating here that relational talk and transactional talk are not mutually exclusive; "relational exchanges and sequences can occur within genres with clear transactional goals” and vice versa (Koester 2006: 53). Yet, two communicative goals that demand oppositional approaches to negotiating interpersonal relations can be challenging to satisfactorily reconcile in practice (see below).

A second inconsistent intracultural premise relates to the audience for which the prescribed style is designed. Given that prescribed styles are oriented to people (Bell 2009), I examined how the recipients of collections calls were referred to in the data. The fact that I have used the referents "debtor" and "customer" interchangeably throughout this paper is not coincidental; the recipient was referred to as a debtor $39.3 \%$ of the time and as a customer for the remaining $60.7 \%$ in the data itself. When a customer owes money, they do not cease to be a customer; instead they take on the additional identity of a debtor. Hence, the target audience of this prescribed style is a conflation of a customer identity face and a debtor identity face. This is exemplified by two consecutive headings in HTCD in a section that address "types" of customers/debtors: 
Example 23. (HTCD)

\section{Handling Different Customer Types}

\section{Plan for Debtor Type}

Consequently, the style must also attempt to manage the relevant equity and association rights of two competing identity faces: that of someone who is indebted to Electrik on the one hand and that of someone who Electrik wish to appease on the other. The collector is at once legitimately empowered to enact the necessary imposition of demanding money, yet also disempowered by the asymmetry inherent in the public servant-private citizen relationship (see Section 1 and "Role Specifications" in Table 1). Indeed, in one interview I conducted, a collector aptly described the way he had been trained to collect debt as embodying a "helping you [the customer] to pay us [Electrik]" mentality. I propose that this prevailing "helping you to pay us" philosophy, which permeates the prescribed style, may be problematic for both the call centre worker and for the debtor/customer and, therefore, to the respective dynamic judgements each may make regarding the rapport (or lack thereof) between them. Firstly, the local deployment of this style, with its competing orientations to rapport, presented a struggle to the collectors themselves. During discussions with collectors about the linguistic regulation they were subject to in their jobs, allusions to dissonance, such as "balancing acts", "mixed messages" and "being pulled in different directions", were commonplace (cf. tensions between outcomes and time in CCs [Hultgren 2011: 49]). My experience of working in this context also aligns with their accounts. This is unsurprising given the implicit assumption that collectors must attend to the two distinct but nonetheless fused social roles of the debtor who has erred and the customer who is always "right" (Grandey et al. 2004: 399). That the practical application of this style in collections encounters was problematic for the collectors points to a way in which corporate linguistic styling in service jobs may subjectively position the worker "within a site of struggle" (Eustace 2012: 343). Whereas sociolinguistic research on service industries has demonstrated how linguistic regulation can cause friction in the spaces between the CC as the workplace and the surrounding social, regional or national culture (Cameron 2000a, Rahman 2009 etc.), in this pragmatic investigation, the site of struggle is the prescribed style itself because of its inherent contradictions concerning the management of rapport.

Secondly, it is also possible to see how the prescription of this style may be problematic for its intended target; there is also dissonance involved in being faced with linguistic behaviour that may be inconsistently perceived as face-enhancing or face-threatening. If the type of rights and obligations we feel entitled 
to in an encounter in terms of equity and association depend, in part, on our understanding of the social identities and roles we occupy, what happens when not only our role, but also that enacted by our interlocutor, and, by extension, the rapport-relevant information they convey through their speech, is ambiguous? When both interlocutors are at once empowered and disempowered, entitled and indebted, two sets of conflicting behavioural expectations are drawn on when making dynamic judgments about each other's linguistic conduct.

Relational tensions can occur when participants in an interaction focus on or have differing expectations about appropriate rapport management concerns (Spencer-Oatey 2002: 542). This manifests even at the level of expected speech acts. For instance, whereas a self-identifying debtor who is cognizant of their arrears may anticipate demands, a self-identifying customer may interpret unexpected demands as aggressive because they feel entitled to high levels of autonomy and personal consideration. The evidence here suggests that the inconsistent rapport-relevant information communicated by collectors across multiple domains has the potential to foster relational tension, dissatisfaction and disharmony in collections encounters. In my personal experience as a collector in this context, I would suggest that it is not necessarily just the face-threatening demand for payment that may trigger such dissatisfaction or disharmony. Importantly, the ambiguous way that the encounter is designed to be carried out may also contribute to the possible onset of collector-directed verbal aggression. Not only is this debt collection style a site of struggle for the collector in practice, but it may also make them the subject of verbal aggression. Linguistic regulation in CCs has already been seen to contribute to a culture of sanctioned face-attacks. Archer and Jagodziński (2015: 52) argue it is the "close monitoring of what an agent can and cannot say, and how they are expected to say it" that contributes to institutions tacitly accepting callers' attacks to agents' faces. Similarly, it may be the case in this investigation that collectors may be the subjects of customers'/ debtors' face-attacks because of the synecdochical relationship they have with their employers in which stylistic choices are made beyond their control.

\subsection{Effectively managing rapport}

Linguistic predetermination in CCs presupposes the success of the prescribed style; prescription suggests that the (strategic) effects of a linguistic input are predictable and guaranteed, or at least more so than the individualized alternative. However, the evidence here would suggest that the local deployment of this prescribed style may not necessarily be effective for successfully collecting debt (nor for customer service). This lends evidence to Eustace's (2012: 342) argument 
that there may be error in "employers' perceptions" of linguistic standardization having obvious benefits to both companies that prescribe it and the employees that must implement it. As Jagodziński (2013: 174) comments, such codification practices do not always "serve the goals set before them". This is particularly the case if relational tension may be an unwanted corollary of using such a style. Any resulting face-attacks by customers/debtors are not only challenging to handle practically but also demand agents to regulate their emotions. Repeated and prolonged emotional regulation in this workplace is strongly associated with high levels of stress (Grandey et al. 2004; Wegge et al. 2007). As a sector with an already high staff attrition rate because of, for instance, the limited scope for promotion, the addition of stress-related absences is highly undesirable to CCs. Perhaps this ineffectiveness could be addressed in two ways. On the one hand, a "helping you to pay us" philosophy may need to be disbanded, and debt collection and customer service should be treated as discrete tasks. The attempt to communicate antagonistic rapport-relevant information stemmed from the conflation of these prototypically face-threatening and face-enhancing activities. The separation of the two would, for instance, also eradicate the need for linguistic techniques that falsely facilitate the building of rapport. However, the need to perform two tasks with one style may be a consequence of the constant tension between time and efficiency in CCs. Equally, this conflation may be unavoidable for an internal debt collection department, given that collectors will always invariably have some responsibility to the identity faces of their debtors as customers, i.e., to retain custom, there is always some rapport to be maintained.

An alternative and perhaps more tenable solution relates to linguistic agency itself. Simply put, corporate linguistic stylers may need to loosen the synecdochical hold that they have over their employees, thereby, affording agents greater linguistic autonomy. The problem I have identified appears to be symptomatic of a wider problem that (im)politeness researchers have observed in CCs. Jagodziński (2013: 174), for instance, criticizes codification in CCs, concluding that there is an inherent paradox between the institutional expectations made of CC agents and the "very limited, facework means at their professional disposal" to meet those expectations. Likewise, when analyzing complaints calls, Orthaber and Márquez Reiter (2011: 3875) conclude that when the hands of the CC employee are "tied" by institutional restrictions on linguistic behaviour, predictably, no satisfactory resolution is achieved. As an extension of this, I would suggest that in debt collection encounters, especially those that cannot be completely detached from customer service obligations, linguistic idealization may be almost entirely redundant. Given that these interactions require the particularly complex management of rapport, collectors need the flexibility and volition, the choice between a "this way" and "that way", that will enable them to reflexively cope with the many 
facework demands, unpredictability, and potential volatility of collecting debt (Bell 2009). Hence these interactions must be conceptualized by academics and practitioners alike as continuously negotiated, co-constructed and highly particularized encounters. The sort of reflexivity I am proposing is central to Spencer-Oatey's (2005: 116) suggestion that for effective rapport management people must dynamically assess and reassess "their own conditions and reactions" whilst considering whether their interlocutor's face conditions, wants and "interactional expectancies are being fulfilled”.

\section{Conclusion}

This paper has used prescriptive textual materials as an important dataset to examine the rapport management work that call centre agents are trained and instructed to perform in a previously unexplored call centre activity: debt collection. The analytical approach used illustrates how the synthesis of rapport management theory with sociolinguistic conceptions of style may be productively used in pragmatic investigations of prescriptive linguistic styling in call centres. The principles of equity and association in particular were crucial for identifying the inherent contradictions in the rapport-relevant information that the style was intended to convey. These then enabled an understanding of how the style may be problematic for both its users and intended recipients, especially in how it may contribute to a culture of sanctioned face-attacks in call centres. The study of debt collection as a call centre activity in which face-threatening behaviour is potentially bi-directional between public servants and private citizens offers (im) politeness research an avenue through which to diversify the current conception of call centre encounters.

Given the proposed complications that the use of this style may have in practice, future research that is able to access authentic debt collection encounters (see Harrington, forthcoming) might explore the extent to which collectors actually adhere to the prescribed style in practice (cf. Hultgren 2011), and whether the relational tensions I have anticipated do manifest in the form of collector-directed face-attacks. In my experience of working in this context, I anticipate the latter would be the case. I would also be interested to investigate how debt collectors who have no obligation to the identity face of a customer perform collection tasks. Given they may be more explicitly face-threatening, these styles may, for instance, more closely resemble Custers' (2017) conception of debt collection communication as unpleasant, threatening and even violent. 
Acknowledgements: I would like to thank Electrik for their cooperation with this research, the reviewers of a previous version of this paper for their incredibly valuable feedback, and the Department of English at Loughborough University where the masters dissertation on which this paper is based was completed in 2014. This work was supported by the Economic and Social Research Council [grant number ES/J500100/1].

\section{References}

Archer, Dawn \& Jagodziński, Piotr. 2015. Call centre interaction: A case of sanctioned face attack? Journal of Pragmatics 76. 46-66.

Austin, John Langshaw. 1962. How to do things with words. Cambridge: Harvard University Press.

Bell, Allan. 2009. Language style as audience design. In Nikolas Coupland \& Adam Jaworski (eds.), The New Sociolinguistics Reader, 265-275. London: Palgrave Macmillan.

Bousfield, Derek. 2007. Beginnings, middles and ends: A biopsy of the dynamics of impolite exchanges. Journal of Pragmatics 39. 2185-2216.

Bousfield, Derek. 2010. Issues in impoliteness research. In Miriam Locher \& Sage Graham (eds.), Interpersonal Pragmatics, 101-134. Berlin: Mouton de Gruyter.

Brown, Penelope \& Levinson Stephen. C. 1987. Politeness: Some universals in language usage. Cambridge: Cambridge University Press.

Callahan, Laura. 2006. English or Spanish?! Language accommodation in New York City service encounters. Intercultural Pragmatics 3. 29-53.

Cameron, Deborah. 2000a. Styling the worker: Gender and the commodification of Language in the Globalized Service Economy. Journal of Sociolinguistics 4. 323-347.

Cameron, Deborah. 2000b. Good to talk? Living and working in a communication culture. London: Sage Publications.

Cameron, Deborah. 2008. Talk from the top down. Language and Communication 28. 143-155.

Culpeper, Jonathan, Derek Bousfield \& Anne Wichmann. 2003. Impoliteness revisited: With special reference to dynamics and prosodic aspects. Journal of Pragmatics 35. 1545-1579.

Culpeper, Jonathan, Robert Crawshaw \& Julia Harrison. 2008. Activity types and discourse types: Mediating advice in interactions between foreign language assistants and their supervisors in schools in France and England. Multilingua 27. 297-324.

Culpeper, Jonathan. 2011. Impoliteness: Using language to cause offence. Cambridge: Cambridge University Press.

Custers, Anna. 2017. Falling behind: Debtors' emotional relationships to creditors. In Annabelle Mooney \& Evi Sifaki (eds.), The Language of money and debt, 163-185. London: Palgrave Macmillan.

Deville, Joe. 2015. Lived economies of default: Consumer credit, debt collection and the capture of affect. London: Routledge.

Eckert, Penelope. 1996. Vowels and nail polish: The emergence of linguistic style in the preadolescent heterosexual marketplace. The Fourth Berkeley Women and Language Conference in Berkeley, California 
Eckert, Penelope \& Sally McConnell-Ginet. 1999. New generalizations and explanations in language and gender research. Language in Society 28. 185-201.

Eustace, Elizabeth. 2012. Speaking allowed? Workplace regulation of regional dialect. Work, Employment and Society 26. 331-348.

Giles, Howard. 2009. The process of communication accommodation. In Nikolas Coupland \& Adam Jaworski (eds.), The new sociolinguistics reader, 276-286. London: Palgrave Macmillan.

Grandey, Alicia, David Dickter \& Hock-Peng Sin. 2004. The customer is not always right: Customer aggression and emotion regulation of service employees. Journal of Organisational Behaviour 25. 397-418.

Harrington, Leigh. Forthcoming. Polite and impolite linguistic strategies in credit control encounters. University of Nottingham PhD thesis.

Heller, Monica. 2003. Globalization, the new economy, and the commodification of language and identity. Journal of Sociolinguistics 7. 473-492.

Holmes, Janet. 2000. Doing collegiality and keeping control at work: Small talk in government departments. In Justine Coupland (ed.), Small Talk, 32-62. Harlow: Pearson.

Hood, Susan \& Gail Forey. 2008. The interpersonal dynamics of call-centre interactions: Co-constructing the rise and fall of emotion. Discourse and Communication 2. 389-409.

Hultgren, Anna Kristina. 2011. Building rapport with customers across the world: The global diffusion of a call centre speech style. Journal of Sociolinguistics 15. 36-64.

Hultgren, Anna Kristina \& Deborah Cameron. 2010. Communication skills in contemporary service workplaces: Some problems. In Gail Forey \& Jane Lockwood (eds.), Globalization, communication and the workplace: Talking across the world, 41-56. London: Continuum.

Jagodziński, Piotr. 2013. Impoliteness strategies in a British airline call centre: A pragmatic analysis of customer service interactions. Manchester: Adam Mickiewicz University PhD thesis.

Jagodziński, Piotr \& Archer, Dawn. 2017. Silence in conflictive call centre service encounters: conversational resource or 'dead air'?. Paper presented at $10^{\text {th }}$ International Symposium on Politeness, York St John University, $12^{\text {th }}-14^{\text {th }}$ July.

Jaworski, Adam. 1993. The power of silence: Social and pragmatic perspectives. London: Sage. Koester, Almut. 2006. Investigating workplace discourse. London: Routledge.

Kurzon, Dennis. 2007. Towards a typology of silence. Journal of Pragmatics 39. 1673-1688.

Leidner, Robin. 1993. Fast Food, Fast Talk: Service Work and the Routinization of Everyday Life. Berkeley: University of California Press.

Levinson, Stephen. C. 1992. Activity types and language. In Paul Drew \& John Heritage (eds.), Talk at work: Interaction in institutional settings, 66-100. Cambridge: Cambridge University Press.

Limberg, Holger. 2009. Impoliteness and threat responses. Journal of Pragmatics 35. 1376-1394.

Locher, Miriam \& Richard Watts. 2005. Politeness theory and relational work. Journal of Politeness Research 1. 9-33.

Márquez-Reiter, Rosina \& Patricia Bou-Franch. 2017. (Im)politeness in service encounters. In Jonathan Culpeper, Michael Haugh \& Dániel Kádár (eds.), The Palgrave handbook of linguistic (Im)politeness, 661-688. London: Palgrave.

Mehrabian, Albert. 1968. Communication without words. Psychology Today 2(9). 52-55.

Merritt, Marilyn. 1976. On questions following questions in service encounters. Language in Society 5. 315-357. 
Mills, Sara. 2003. Gender and politeness. Cambridge: Cambridge University Press.

Mooney, Annabelle \& Evi Sifaki. 2017. The view from the ground. In Annabelle Mooney \& Evi Sifaki (eds.), The language of money and debt, 1-30. London: Palgrave Macmillan.

Moore, Emma \& Robert Podesva. 2009. Style, indexicality, and the social meaning of tag questions. Language in Society 38. 447-485.

Mullany, Louise. 2006. 'Girls on tour': Politeness, small talk and gender in managerial business meetings. Journal of Politeness Research 2(1). 55-77.

Orthaber, Sara, \& Rosina Márquez-Reiter. 2011. 'Talk to the hand': Complaints to a public transport company. Journal of Pragmatics 43. 3860-3876.

Orthaber, Sara \& Rosina Márquez-Reiter. 2016. When routine calls for information become interpersonally sensitive. Pragmatics and Society 7(4). 638-663.

Rahman, Tariq. 2009. Language ideology, identity and the commodification of language in the call centres of Pakistan. Language in Society 38. 233-58.

Schnurr, Stephanie. 2009. Leadership discourse at work: Interactions of humour, gender and workplace culture. Basingstoke: Palgrave Macmillan.

Searle, John. 1976. A classification of illocutionary acts. Language in Society 5. 1-23.

Sonntag, Selma. 2009. Linguistic globalization and the call center industry: Imperialism, hegemony or cosmopolitanism. Language Policy 8. 5-25.

Speer, Susan \& Elizabeth Stokoe. 2014. Ethics in action: Consent-gaining interactions and implications for research practice. British Journal of Social Psychology 53. 54-73.

Spencer-Oatey, Helen. 2002. Managing rapport in talk: Using rapport sensitive incidents to explore the motivational concerns underlying the management of relations. Journal of Pragmatics 34. 529-545.

Spencer-Oatey, Helen. 2005. (Im)politeness, face and perceptions of rapport: Unpacking their bases and interrelationships. Journal of Politeness Research 1. 95-119.

Van Dijk, Teun A. 1977. Text and context: Explorations in the semantics and pragmatics of discourse. London: Longman.

Warhurst, Chris \& Dennis Nickson. 2007. A new labour aristocracy? Aesthetic labour and routine interactive service. Work, Employment and Society 21. 785-98.

Wegge, Jurgen, Joachim Vogt, \& Christiane Wecking. 2007. Customer-induced stress in call centre work: A comparison of audio- and videoconference. Journal of Occupational and Organizational Psychology 80. 693-712.

Wenger, Etienne. 1998. Communities of practice: Learning, meaning and identity. Cambridge: Cambridge University Press.

\section{Bionote}

\section{Leigh Harrington}

Leigh Harrington is a PhD student in the School of English at the University of Nottingham, UK. Her research topic concerns the application of im/politeness theory to complex professional settings, specifically exploring the strategic management of face in credit union debt collection interactions. 